\title{
Cinema e literatura: pandemia, deslocamentos, e (in)certezas como "Vidas Severinas"
}

\section{Cinema and literature: pandemic, displacements, and (un)certainties as "Vidas Severinas"}

\author{
Suely dos Santos Silva ${ }^{1 *}$, Maria José Ferreira de Moraes $^{1}$ Douglas Soares Freitas ${ }^{1}$, Rosângela \\ Mendonça de Oliveira ${ }^{1},{ }^{1}$
}

\begin{abstract}
RESUMO
Cinema, educação e literatura, abordados neste artigo, enfatizam como as artes contribuem nesse contexto atípico, desolador e enigmático que vivenciamos. O tema não foi esgotado, mas contribuímos para o debate sobre os desafios que enfrentamos no contexto pandêmico e pós-pandêmico. O cinema e a literatura são ferramentas mediadas por educadores/profissionais que potencializam saberes diversos. Morte e Vida Severina reflete como as pessoas vivenciam há mais de 60 anos realidades fundidas nos séculos XX e XXI. O objetivo é debater progressos e retrocessos que o povo brasileiro, especialmente o sertanejo, sofrem ao longo de décadas com a falta relativa e às vezes total de condições de vida digna, estes auxiliam na aprendizagem, ampliam o capital cultural. A abordagem metodológica é a praxiológica, de Pierre Bourdieu, a qual consiste em pensar as categorias de análise de forma relacional. Os resultados indicam que a literatura e o filme podem facilitar a apropriação do capital cultural dos(as) Severinos(as) fictícios e reais que representam a dura realidade do povo brasileiro menos favorecido economicamente e que enfrentam mazelas do descaso das políticas públicas agravado em tempos de pandemia de COVID-19.
\end{abstract}

Palavras-chave: Educação; Cinema; Literatura.

\section{ABSTRACT}

\begin{abstract}
Cinema, education and literature, covered in this article, emphasize how the arts contribute to this atypical, desolate and enigmatic context that we experience. The topic has not been exhausted, but we have contributed to the debate on the challenges we face in the pandemic and post-pandemic context. Cinema and literature are tools mediated by educators/professionals who enhance diverse knowledge. Morte e Vida Severina reflects how people, for more than 60 years, have experienced fused realities in the 20th and 21st centuries. The aim is to debate the progress and setbacks that Brazilians have suffered over the decades with the relative and sometimes total lack of dignified living conditions, especially with the challenges caused by the Covid-19 pandemic, these. help in learning, expand cultural capital. The methodological approach is the praxiological one, by Pierre Bourdieu, which consists of thinking about the categories of analysis relationally. The results indicate that literature and the film can facilitate the appropriation of cultural capital the fictitious and real Severinos(as) that represent the severe Brazilian reality, the
\end{abstract}

\footnotetext{
${ }^{1}$ Universidade Federal de Goiás

*E-mail:zezedemoraes@gmail.com;douglasfreitas24@gmail.com; mendonçadeoliveirarosangela@gmail.com; suely_silva@ufj.edu.br
} 
economically disadvantaged ones who face neglect of public policies aggravated in times of pandemic covid19.

Keywords: education; cinema; literature; poverty; pandemic.

\section{INTRODUÇÃO}

A importância da educação e da ciência em tempo de crise demonstra que o tema abordado texto se faz atual e significativo no momento vivenciado pelo isolamento social em decorrência da pandemia do novo Corona vírus. Atualmente, o vírus já tem diversas mutações cada vez mais agressivas e é crescente a necessidade de conscientização e o cumprimento do distanciamento social como meio de contê-lo e preservar vidas. As medidas sanitárias necessárias para o combate à pandemia no país não foram e não estão sendo eficazes e/ou não se fizeram prioridades para o Governo Federal e parte da população até o momento. Propomos a reflexão sobre a importância da escola, mesmo em tempos de crise, ser indispensável. Consideramos que as Web aulas, Webinários, Webconferências dentre outras atividades, que acontecem virtualmente, tentam levar o conhecimento e reflexões da atualidade, mas são insuficientes.

Debater a educação de forma geral e sobretudo a que se dá em forma de atividades escolares, que visam à certificação em graus/anos de escolaridade, têm exigido diferentes ações didáticas que vão desde o uso das novas tecnologias, até questões sobre como garantir a readaptação do espaço e dos tempos de aprendizagem. Nesse sentido, o cinema e a literatura têm muito a oferecer para aulas diversificadas. A escolha do documentário "Morte e Vida Severina, 60 anos", de Cristina Aragão e Gerson Camarotti, e do livro "Morte Vida Severina", de João Cabral de Melo Neto, foi motivada por sua dimensão sociológica. Os(as) Severinos(as) protagonistas dos dois materiais de pesquisa se fundem, mesmo com 60 anos de distância um do outro, compreendendo que são protagonistas de realidades imutáveis para diversos personagens do livro e da vida real apresentada no documentário. Os personagens de ambas as obras se encontram sem perspectivas de superação das gerações passadas de 'Severinos(as)'. Alguns aspectos permaneceram e outros até pioraram. Estes personagens, semelhantes ou não, melhores ou não na ascensão social, no campo cultural, tecnológico ou educacional, compreendem a realidade brasileira ao longo das seis décadas e apontam o descaso das três esferas de governo com 
a aplicação dos recursos públicos destinados ao desenvolvimento dos lugares. O documentário apresenta várias entrevistas dos personagens 'Severinos(as)' e o deslocamento motivado pelo desejo e confiança no futuro melhor por meio de emprego e da frequência à escola que eles imaginam conseguir. São brasileiros que não tiveram a oportunidade de estudar, mas que veem na trajetória escolar dos filhos a chance para que eles tenham desfechos diferentes de 'Severinos(as)'como seus pais. Tanto o livro como o documentário feito 60 anos após, portanto, a fim de verificar se teria havido mudanças significativas na vida dos primeiros deslocados, infelizmente mostraram que nem a realidade de origem e nem a de destino melhoraram, demonstrando que o descaso governamental para os mais pobres está presente tanto no espaço rural quanto no urbano.

\section{LITERATURA E CINEMA: PROGRESSOS E REGRESSOS 60 ANOS DE MORTE E VIDA SEVERINA}

A expedição que refez a saga fictícia de Morte e Vida Severina e que representa a jornada verídica de inúmeros Severinos(as) anônimos no Brasil oportunizou aos entrevistados do documentário conhecer o 'maior e mais famoso' poema de João Cabral de Melo Neto que é "Morte e Vida Severina”. Escrito em 1955 por João Cabral de Melo Neto, o poema Morte Vida Severina apresenta em sua história algo instigante, a começar pelo número de páginas que este poema abrange. O poema está redigido em quarenta e duas laudas as quais discorrem sobre a viagem do personagem 'Severino'. Conforme relatos do jornalista Camarotti ao jornalista Daniel França, do Boletim da Unicamp (2015), o texto Morte e Vida Severina foi escrito a pedido da escritora Maria Clara Machado, para que fosse encenado pelo Tablado (Cursos de improvisação e teatro no Brasil, fundado em 1951 por ela). Após feita a leitura da obra, no entanto, a escritora devolveu o texto ao autor e afirmou que atores pertencentes ao grupo que comandava não possuíam condições cênicas para representá-lo. O texto até então escrito em forma de teatro para tal fim não teve finalidade. João Cabral de Melo Neto, no mesmo período, estava na fase final da escrita de um livro. O editor considerava, porém, a quantia de poemas reduzidos. Sendo assim, o autor de Morte e Vida Severina retirou as marcações do texto para teatro e o inseriu para “completar" o livro até então intitulado Duas Águas. De acordo França (2015), o autor ficou vislumbrado ao saber que amigos, como Vinicius de Moraes, ficaram encantados com o poema. 
Este fato nos faz (re)pensar sobre a magnitude da literatura lançada nas palavras do poema. Em conformidade com Cândido (2011, p. 176), "a literatura aparece claramente como manifestação universal de todos os homens em todos os tempos. Não há povo e não há homem que possa viver sem ela, isto é, sem a possibilidade de entrar em contato com alguma espécie de fabulação". Percebemos no documentário o apreciar de cada palavra, de cada verso do poema, esse encantamento descrito pelo autor sobre o fabular. É visível e indescritível as reações e sensações que o poema escrito há mais de 60 anos aflora nas reflexões sobre a realidade dura e palpável da vida experienciada por outras gerações em pleno século XXI.

O poema traduz crises e dificuldades enfrentadas pelos estratos menos favorecidos do estado de Pernambuco e permite (inter)relacionar que a mesma realidade está espalhada por diversos estados da federação brasileira, demonstrada nos baixos índices de escolarização que afeta sobretudo os meninos/moços. De acordo com Nogueira e Nogueira (2004), do ponto de vista de Bourdieu, todo indivíduo é definido em sentenças socialmente herdadas. Essa sentença agrega alguns tipos de capitais que podem ser colocados a serviço do êxito escolar. Fazem parte dessa sentença, segundo Nogueira e Nogueira (2004, p. 59), “o capital econômico, tomado em termos de bens e serviços a que ele dá acesso, o capital social, definido como conjunto de relacionamentos sociais influentes mantidos pela família”. Nessas sentenças também estão inclusos o capital cultural institucionalizado, o diploma e o capital cultural incorporado, o uso do que a pessoa aprendeu.

Figura 1 - Morte Vida Severina

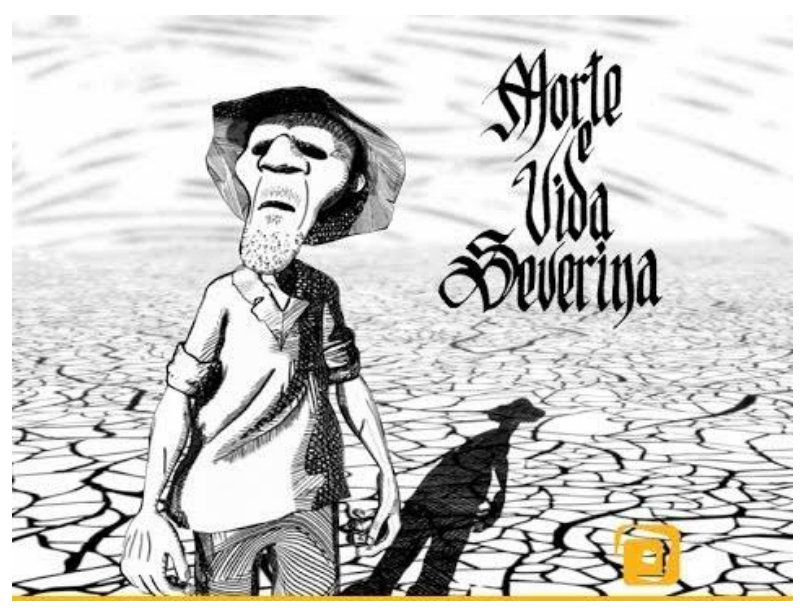

Fonte: https://www.youtube.com/watch?v=clKnAG2Ygyw 
A figura 1 representa o personagem principal do livro Morte e Vida Severina sob o sol escaldante do sertão nordestino. Na imagem, percebe-se o olhar longínquo e perdido do personagem. Ela representa o pensamento de desilusão, desânimo, incapacidade e impotência frente à dura e penosa realidade vivida. Ao fundo da figura simula-se o vento que parece assoviar sobre o deserto e assinala a escassez de umidade do ar existente naquele ambiente e consequentemente o solo rachado decorrente da falta de chuvas e que enquanto causa natural não encontrou até hoje uma solução política. A configuração sociológica exposta nestas obras caracteriza questões emblemáticas presentes na realidade vivida, mesmo 60 anos atrás. Essa realidade esbarra na falta de escolaridade comum a estes espaços. Em tempos de pandemia, esse aspecto acentua as desigualdades de todas as ordens, as quais são crescentes. Nesse sentido, Bourdieu (2007a) afirma que a desigualdade ocorrida no processo de aquisição e incorporação do capital escolar e cultural, obtido por cada pessoa, "encontra na origem de diferenças entre detentores de um capital escolar idêntico podendo resultar, também, do fato de que o mesmo diploma pode corresponder a períodos de escolarização bastante desiguais" (BOURDIEU, 2007a, p. 79). Isso se dá por conta do "(efeito de conversão desigual do capital cultural escolarmente adquirido): os efeitos diretos ou indiretos de um ou vários anos e estudos nem sempre são sancionados, de fato, pelo diploma" (BOURDIEU, 2007a, p. 79. Grifos do autor). A aquisição do capital cultural e escolar de cada um é, para Bourdieu, um meio a ser usado de diferentes formas, independente do curso realizado por sujeitos distintos. O período de estudo pode não corresponder a tempos iguais, o que permite a desigualdade do capital cultural adquirido. Diversos personagens ao serem entrevistados no documentário 'Morte e Vida Severina - 60 anos depois', embora demonstrem disparidade na apropriação do capital cultural escolar, querem que seus filhos avancem para além.

Para Bourdieu (2007a), o capital cultural e escolar dos estudantes varia de acordo com a frequência à escola e depende do nível, se Ensino Médio ou Ensino Superior. Se em ambos os casos não tiverem sido concluídos, um terá menos tempo de aquisição de capital escolar que o outro, o que propaga as desigualdades. Ele ressalta, ainda, que além do tempo dedicado ao capital escolar, também existe a distinção entre as instituições, diferenças dos métodos pedagógicos, de professores, engajamento pessoal, familiar e social e muitos outros fatores. Afirma o autor que a defasagem aumenta à medida que os estratos sociais vão cursando níveis de ensino mais avançados. A crescente trajetória social segue as distinções associadas ao capital cultural herdado, visíveis entre os estratos 
menos e/ou mais favorecidos economicamente, fato que corresponde ao investimento cultural não assegurado pela instituição escolar. Conforme Bourdieu (2007a, p. 82), "a família e a escola funcionam, inseparavelmente, como espaços em que se constituem, pelo próprio uso, as competências julgadas necessárias em determinado momento, assim como espaços em que se forma o valor de tais competências”. Desta maneira, percebe-se como o mercado fortalece e controla de acordo com padrões negativos ou positivos o desempenho, aceitando o que é favorável e desaprovando o que não é, condenando dessa forma as disposições destituídas de valor.

Ainda em conformidade com Bourdieu (2007b, p. 74), “o capital cultural pode existir sob três formas: no estado incorporado, ou seja, sob a forma de disposições duráveis do organismo". São exemplos o domínio da língua, o gosto refinado pelas artes, lazer, vestuário, decoração, paladar, esportes, conhecimentos do universo escolar entre outros. No estado objetivado, aquisição e uso "sob a forma de bens culturais - quadros, livros, dicionários, instrumentos, máquinas" (BOURDIEU, 2007b, p. 74). Por último, no estado institucionalizado, tem-se uma "forma de objetivação em que é preciso se colocar à parte porque, como se observa em relação ao certificado escolar, ele confere ao capital cultural - de que é supostamente, a garantia-propriedades inteiramente originais" (BOURDIEU, 2007b, p. 74). Os três tipos de capitais são imprescindíveis na escola e o cinema e a literatura conjugam dois deles. O tamanho do investimento que famílias e estudantes fazem no percurso escolar está ligado ao retorno provável na obtenção do certificado, "são o produto desse encontro entre duas histórias, uma no estado objetivado, a outra no estado incorporado, que são subjetivamente concedidas" (BOURDIEU, 2019, p. 155). De maneira mais difundida, a aquisição de capital cultural se dá na inculcação e assimilação na transmissão da 'herança familiar e social, o que facilita a aprendizagem de códigos e matérias escolares, agregando dessa forma uma ligação entre o mundo da família e o mundo da escola'. O cinema e a literatura na família e na escola facilitam essa aquisição.

O capital cultural institucionalizado geralmente é formado por títulos escolares. No entanto, Bourdieu salienta que o patrimônio repassado pela família acrescenta também outros componentes que fazem parte da subjetividade da pessoa. Segundo Bourdieu (2019), para que haja esses gostos é preciso que haja 'bens classificados em 'bom' ou 'mau' gosto, 'distintos' ou 'vulgares', classificados e ao mesmo tempo classificadores" (p. 154). Os bens são "hierarquizados e hierarquizantes, e pessoas dotadas de princípios 
de classificação, de gostos, que lhes permitam identificar entre esses bens, aqueles que lhes convêm, aqueles que são 'do seu gosto'” (BOURDIEU, 2019, p. 154).

Segundo Nogueira e Nogueira (2004, p. 60), “o capital cultural (sobretudo, na sua forma incorporada) é o elemento da herança familiar que teria o maior impacto na definição do destino escolar”. Bourdieu (2007b) equipara a redução que viabiliza o peso do fator econômico, relativamente ao cultural e que explica as desigualdades escolares. O autor enfatiza que a posse do capital cultural poderia favorecer o desempenho escolar conforme a família possibilitasse a aprendizagem de códigos e conteúdos presentes, por exemplo, nas obras literárias e cinematográficas e que precisam estar na escola, sobretudo em tempos de aulas remotas. Na verdade, o capital econômico e social trata-se de um “conjunto de recursos atuais ou potenciais que estão ligados à posse de uma rede durável de relações mais ou menos institucionalizadas de ou Inter reconhecimento. Em outros termos, a vinculação a um grupo como conjunto de agentes" (BOURDIEU, 2015, p. 75. Grifos do autor) os quais acarretam na maioria das vezes como exclusivo meio de concentração do capital cultural com os que já possuem outros tipos de capital. O capital econômico possibilita o acesso a diversos bens culturais com custos mais elevados, como viagens de estudos e admissão em determinadas instituições de ensino. Os privilégios e a utilização dessas oportunidades, no entanto, estão estritamente ligados ao capital cultural antecipadamente recebido e aceito. Para Nogueira, Nogueira (2004), em conformidade com Bourdieu, cada membro do grupo social tende a fazer projetos, dentro de suas limitações, mais ou menos ambiciosos e investe parte maior ou menor de empenho, considerando recursos financeiros, energia física e tempo na educação escolar dos seus filhos de acordo com as possibilidades de sucesso esperado.

Os pais entrevistados no documentário Morte e Vida Severina 60 Anos Depois procuram investir o pouco tempo e os recursos que possuem na potencialidade dos seus filhos Severinos(as). Dispõem para eles o incentivo para estudar, uma vez que para eles essas possibilidades foram negadas. Cada família proporciona o capital cultural que possui aos seus descendentes. Vinculado ao capital cultural oferecido está o capital econômico. Os personagens do livro Morte e Vida Severina e os do documentário Morte e Vida Severina 60 Anos Depois possivelmente não tiveram acesso aos bens culturais como cinema, viagens, visitas a museus e outros por não possuírem o capital econômico que lhes dariam tais possibilidades. A frequência deles à escola, portanto, pode ser ainda mais dificultada em tempos de pandemia. 
De acordo com Gualda (2011), o produto cinematográfico como versão do produto literário é completamente independente. No entanto, simultaneamente, estão estreitamente relacionados. Desde o instante em que não é mais considerada a tradução como recriação da realidade na obra literária, a versão passa a ser entendida como transformação, de maneira que o resultado dessa evolução surge com total disposição recente e o texto deve ser notado como produto/obra autônoma que não pode ser apropriada, julgada ou entendida se considerada meramente imitação. A autora afirma que não foi exclusivamente o cinema que aprendeu com a literatura, o oposto também aconteceu. Essa simbiose permite a interferência da linguagem fílmica e literária. Boa parte dos autores do século XX, segundo ela, "o ato de assistir a um filme ou ler um livro, sugere que nos envolvemos num mundo novo e, devido a isso, temos diferentes experiências cada vez que entramos em contato com a obra" (GUALDA, 2011, p. 209). Em conformidade com Silva (2017, p. 43), “em todas as culturas, ocidentais ou orientais, as pessoas se dispõem a refletir sobre a realidade por meio do cinema". Neste momento pandêmico que tanto tem exigido das instituições escolares e dos profissionais que nelas atuam, a cultura e a arte ajudam a atividade docente.

Do livro Morte Vida Severina para o documentário que revisita a obra percebemos a transição dos personagens por três gerações. Conforme Melo (2013), frequentemente nas narrativas jornalísticas como nas pessoais o sujeito-autor gera uma nova situação com base em fatos que já se passaram. Essa nova conjuntura não é um retrato fiel da realidade, no entanto é a sua reprodução. Neste caso dos 60 anos do livro, a reprodução se aproxima da realidade vivida há seis décadas por Severinos(as) que representam papéis parecidos ou mesmo idênticos aos descritos pelo escritor João Cabral de Melo Neto. Dessa forma, Melo (2002, p. 29) acrescenta que "mesmo configurando-se como um discurso sobre o real, documentários e reportagens não são reflexos, mas construções da realidade social". Assim sendo, na reportagem ou no documentário não se permanece frente à documentação, e sim diante do processo ativo de fabricação de significados, conceitos e valores.

O documentário Morte e Vida Severina 60 Anos Depois, ao narrar a história do livro, utiliza equipe de jornalistas que percorreram um mil e quatrocentos quilômetros em duas semanas refazendo o percurso vivido pelo personagem Severino, mostrando uma realidade que ao mesmo tempo se entrelaça com a realidade de tantos Severinos(as) pelo Brasil afora na busca por um novo destino, independente que seja ele para o litoral. São 
os Severinos(as) da caatinga, do cerrado, dos pampas, da mata amazônica, do pantanal, são histórias que se fundem e se confundem em enredos de disparidades e desigualdades evidentes que muitos não querem ver.

Muitos brasileiros migram de seus estados em busca de qualidade de vida que muitas vezes não se concretiza. Como é exemplificado, vários indivíduos entrevistados saíram de sua terra natal e encontram uma pobreza ainda maior do que a que deixaram no sertão. Severino deixou o Capibaribe ${ }^{2}$ do sertão quase sem vida e reencontrou o mesmo na metrópole, cheia de contaminação, praticamente morto.

Da água contaminada e suja com coliformes fecais dos animais do interior do sertão e consumida/dividida com os sertanejos, agora na capital é água suja, contaminada por "animais humanos" e consumida pelos migrantes e demais excluídos ao direito ao saneamento básico, educação, saúde, habitação. Os esgotos lançados no Capibaribe contaminam os menos favorecidos, que utilizam dessa água imprópria para a manutenção da 'Vida Severina'. Um entrevistado no documentário "Morte e Vida Severina, 60 anos" chega à conclusão de que existem várias situações em que as condições atuais de 'Severino(a)' está pior do que há sessenta anos atrás. Muitos residem sobre as palafitas, se alimentam dos siris que conseguem apanhar no lamaçal contaminado em que vivem. Não existe saneamento básico, muitas casas não possuem banheiro. Os moradores se banham na mesma água em que evacuam e na qual é lançado o esgoto dos bairros onde residem os estratos mais afortunados e também onde há a presença das indústrias poluentes.

O documentário mostra que os 'Severinos(as)' que permaneceram no sertão criaram novos habitus que, segundo Bourdieu (1994), trata-se de um "sistema de disposições duráveis, estruturas estruturadas predispostas a funcionar como estruturas estruturantes, isto é, como princípio gerador e estruturador das práticas e das representações que podem ser objetivamente 'reguladas' e 'regulares"' (BOURDIEU, 1994, p. 60). Com o apoio das informações, tecnologias e investimento no social, puderam escrever novas histórias e se reinventaram defronte às adversidades apresentadas pelo sertão. As cisternas que são abastecidas com as águas das chuvas que caem no telhado, escoam pelas calhas e enchem os reservatórios, o que melhorou a qualidade de

2 O Rio Capibaribe é um dos rios do estado de Pernambuco, no Nordeste do Brasil. Seu nome é originário da língua tupi e significa na água de capivara ou dos porcos selvagens. Disponível em https://biblioteca.ibge.gov.br/ 
vida dos 'Severinos(as)' que permaneceram na terra natal. Antes, eles disputavam com os animais as águas sujas represadas nas barragens. Outro avanço apresentado na reportagem que comprova a mudança do habitus do sertanejo está na adaptação dos períodos de estiagem e de chuvas. Muitos sertanejos compreenderam que a terra possui um período de "dormência" e que eles precisam se preparar para enfrentar essa realidade anualmente, o que faz com que possam sofrer menos, pois podem armazenar comida e água enquanto a terra 'dorme'. A diversificação de plantação e da criação ajudou a saciar a fome do sertanejo que passou a entender que a informação e o estudo podem auxiliar na qualidade de vida do indivíduo.

Muitos sertanejos permaneceram no sertão. Quando a terra seca, retiram-se para outros estados em busca de trabalho. São Severinos que de três em três meses se ausentam da casa. Quando a chuva cai, a vida se renova e o Severino à sua casa retorna.

\section{SEVERINOS(AS) E A PANDEMIA: SEM LUGAR PARA MIGRAR}

De tantas lutas e esforços nós nos (re)vivemos de 'Vida Severinos(as)'. A pandemia da Covid 19 nos traz a mesma angústia e incertezas vividas pelo personagem de João Cabral de Melo Neto. Mas para onde correr? Para o Pantanal, Pampa, Cerrado, Caatinga, Mata Atlântica? Somos Severinos reféns das políticas públicas mais do que nunca na atualidade. Não adianta migrar, o desfecho é eminente, o que poderia salvar vidas de Severinos(as) são ações que infelizmente não dependem exclusivamente deles. Vivemos em conflitos políticos cujos líderes não assumem a responsabilidade de preservar/salvar vidas. Jogo de interesses que anulam e pisoteiam os menos favorecidos social, cultural e economicamente.

Com o inesperado aparecimento do Corona vírus no ano de 2020 e sua rápida disseminação, como podemos perceber na figura 2 , houve e ainda há a necessidade do isolamento social para evitar a contaminação em massa. Diversas adaptações ocorreram, principalmente no meio educacional em relação ao mundo digital, tanto na rede pública quanto na rede particular de ensino. Aplicativos de vídeo conferência, redes sociais, aulas remotas surgiram em meio ao inesperado para auxiliar o processo de ensino aprendizagem. Como afirma Cordeiro (2020), "reaprender a ensinar e reaprender a aprender são os desafios em meio ao isolamento social na educação de nosso país". Entre adaptações e tentativas percebemos que há um abismo social para acessar o 
conhecimento. De acordo com Cordeiro (2020), "é importante afirmar que os desafios são imensos, dentre eles, podemos destacar que as ferramentas remotas precisam ter parâmetros de qualidade, para que tenham maior eficácia, e que as desigualdades de acesso às tecnologias são enormes" (CORDEIRO, 2020, p. 3). Mesmo com todas essas dificuldades, essa continua sendo uma das alternativas mais viáveis, mesmo excluindo uma parcela.

As tecnologias e seus recursos manifestam-se no espaço virtual inacreditável para muitos educadores. "Esse novo formato faz com que os professores saiam de suas salas de aula e transformem suas casas, que antes eram ambientes apenas de estudo, descanso e relações familiares, em espaços de ensino não formal" (CARVALHO et al, 2020, p. 74348). Surpreendidos, esses profissionais tiveram que se adaptar às mudanças em um mínimo espaço de tempo. Não houve prazo para formação. A interrupção das aulas presenciais e o princípio das aulas remotas foram ações tomadas pelos governantes na tentativa conter a propagação da pandemia e os prejuízos causados no espaço educacional pela COVID-19. A necessidade de que as ferramentas tecnológicas sejam de qualidade, eficazes, é extrema, mas sabemos que a realidade de crianças e educadores não condiz com a situação do ensino que estamos vivenciando, porém, apesar de muitos entraves, as aulas remotas podem vir atenuar o atraso na aquisição do capital cultural escolar enquanto as aulas presenciais não forem retomadas.

A literatura e o filme em tempos de pandemia são ferramentas aliadas do professor. $\mathrm{O}$ filme tem a possibilidade de acrescentar e favorecer o processo de aquisição do conhecimento apesar de sabermos que grande parte dos estudantes não possui acesso para assisti-lo. Esta metodologia visa a agregar valor para reduzir as defasagens da aprendizagem, sendo utilizada em diversas disciplinas para contribuir e fortalecer o conteúdo abordado bimestralmente. Para Xavier (2008, p. 15), “o cinema que ‘educa’ é o cinema que faz pensar, não só o cinema, mas as mais variadas experiências e questões que coloca em foco". A questão abordada vai além da utilização do filme como forma de transmitir conteúdos, ele impulsiona a reflexão e o debate.

De acordo com Freitas; Lopes e Silva (2021)

O cinema por tudo que foi elencado é seguramente um dos meios que há mais de 100 anos só faz crescer uma poderosa forma de fazer chegar às pessoas, especificamente no espaço escolar, conhecimentos, transmitir ideias, debater assuntos, tecer contra-argumentos e tomar para si e fazer uso criativo dos elementos da cultura do nosso país. Se a 
escola deve ser o lugar que desenvolve o protagonismo infantil/juvenil/adulto, por meio do cinema é possível conseguir que se aprendam conteúdos, formas de resistir e de lutar, etc (FREITAS; LOPES; SILVA, 2021, p. 219).

No processo educativo é fundamental que os estudantes desenvolvam argumentação e contra-argumentação como forma de aquisição e uso do capital cultural. Dessa forma este tem a propensão a maior interiorização, corroborando assim para o desenvolvimento pleno do multiletramento, por meio dos diferentes formas de linguagem, dentre as quais o cinema se enquadra.

\section{CONSIDERAÇÕES FINAIS}

Ao falarmos sobre o cinema, filme e literatura como fomentadores em tempos de desolamento, incertezas nas certezas vividas em 'Vidas Severinas', percebemos que as artes podem auxiliar e contribuir para a educação principalmente em momentos com estes de isolamento social que estamos enfrentando. A abordagem sociológica do documentário e do livro é ampla, atual e instigante, pois funde histórias ficcionais com reais de Severinos(as) ao longo dos tempos.

Ressaltamos a necessidade e a importância da educação e da tecnologia em tempos de crise e principalmente no isolamento social. Sabemos que o que temos disponível hoje não é o ideal, no entanto é uma forma de tentar assegurar um pouco de conhecimento aos estudantes, apesar das desigualdades sociais e econômicas que vivenciamos na escola pública. Urgente se faz a necessidade de investimento público na área educacional para os menos favorecidos economicamente para tentar equiparar o direito ao acesso às aulas remotas.

De modo geral, compreendemos que a saga vivida pelos Severinos(as) personagens fictícios e reais representa a dura realidade do povo brasileiro menos favorecido economicamente, que, independentemente do local onde vive, enfrenta as mazelas do descaso das políticas públicas, tanto na educação, quanto na moradia, saúde, saneamento básico, se estendendo para outras esferas o rol de exclusões. Os desafios são grandes, não trazemos respostas prontas, mas fazemos apontamentos de que a literatura e o cinema, aliados às tecnologias, podem auxiliar, possibilitar, ampliar e facilitar a aquisição do capital cultural escolar. Na certeza de deixar o sertão e acompanhar o Capibaribe na busca de vida melhor, Severinos(as) procuram assegurar aos filhos 
histórias diferentes das suas e acreditam que os Severinos(as) mirins possam traçar finais diferentes dos seus, confiantes na educação escolar.

\section{REFERÊNCIAS}

BOURDIEU, P. Esboço de uma Teoria da Prática. In: ORTIZ, R. (Org.). A sociologia de Pierre Bourdieu. São Paulo: Editora Ática, 1994, n. 39, p. 46-86.

BOURDIEU, P. A Distinção: crítica social do julgamento. São Paulo: Edusp, 2007a.

BOURDIEU, P. Os três estados do capital cultural. In: NOGUEIRA, M. A.; CATANI, A. M. (Org). Escritos de educação. 12ª ed. Petrópolis, RJ: Vozes, 2007b. p. 71-79.

BOURDIEU, P. O capital social - notas provisórias. In: NOGUEIRA, M. A.; CATANI, A. M. (org.). Escritos de educação. 16a ed. Petrópolis, RJ: Vozes, 2015. p. 73-78.

BOURDIEU, P. Questões de sociologia. Trad. Fábio Creder. Petrópolis, RJ: Vozes, 2019.

BRASIL. Painel coronavírus Brasília: Ministério da Saúde; 2021.Disponível em: https://covid.saude.gov.br. Acesso em: 15 mar. 2021.

CÂNDIDO, A. Vários escritos. 5ª ed. Rio de Janeiro: Ouro sobre azul, 2011.

CARVALHO, C. B. et al. Ensino Remoto e Necessidades Específicas: o papel da escola e das famílias. Brazilian Journal of Development, Curitiba, v.6, n.10, p.74345-74355, out. 2020. Disponível em:

https://www.brazilianjournals.com/index.php/BRJD/article/view/17636/14315. Acesso em: 02 set 2020.

CORDEIRO, K. M. de A. O impacto da pandemia na educação: a utilização da tecnologia como ferramenta de ensino Manaus: Faculdades IDAAM; 2020.

Disponível em: http://repositorio.idaam.edu.br/jspui/handle/prefix/1157. Acesso em: 16 abr. 2021

FRANÇA, D. Documentário aborda Morte e Vida Severina 60 anos depois, Boletim Unicap, 2015. Disponível em:http://www.unicap.br/assecom1/documentario-abordamorte-e-vida-severina-60-anos-depois/. Acesso em 01 mar. 2021.

FREITAS, D. S.; LOPES, M. M. R.; SILVA, S. dos S. O USO DO CINEMA EM SALA DE AULA: Um debate necessário nas políticas educacionais e no trabalho docente. In: SILVA, A. J. N. Educação: sociedade civil, estado e políticas públicas 7. Ponta grossa, PR: Atena, 2021. Disponível em:https://www.atenaeditora.com.br/postartigo/45538. Acesso em 20 abr. 2021.

GUALDA, L. C. Literatura e Cinema: elo e confronto. MATRIZEZ, v. 3, n. 2, p. 201- 
220, 2011. Disponível em: http://www.periodicos.usp.br/matrizes/article/view/38267. Acesso em: 14 abr. 2021.

MELO, C. T. V. de. O documentário como gênero audiovisual. Comunicação \&Informação, 5(1/2), 25-40, 2013. Disponível em:

https://doi.org/10.5216/c\&i.v5i1/2.24168. Acesso em: 20 mar. 2021.

MELO NETO, J. C. de. Morte e Vida Severina. Rio de Janeiro: Alfaguara, 2007

NOGUEIRA, C. M. M.; NOGUEIRA, M. A. Bourdieu e a educação. $4^{\mathrm{a}}$ ed. Belo Horizonte: Autêntica, 2004. 128 p.

SILVA, S. dos S. SOCINE mapeamento do cinema brasileiro. Curitiba: CRV, 2017.174p.

XAVIER, I. Um cinema que "Educa" é um Cinema que (nos) Faz Pensar. In: Educação \& Realidade, Porto Alegre, v. 33, n.1, p. 13-20, jan./jun. 2008.

\section{Filmografia}

MORTE e Vida Severina 60 anos depois. Roteiro: Cristina Aragão. Rio de Janeiro: Globo, 2015. (60 min.)

\section{Recebido em: 01/09/2021}

Aprovado em: 20/09/2021 